\title{
Who are the early adopters of new academic fields? Comparing four perspectives on the institutionalization of degree granting programs in US four-year colleges and Universities, 1970-2005
}

\author{
Steven Brint • Kristopher Proctor • Robert A. Hanneman • \\ Kerry Mulligan $\cdot$ Matthew B. Rotondi $\cdot$ Scott P. Murphy
}

Published online: 9 August 2010

(C) The Author(s) 2010. This article is published with open access at Springerlink.com

\begin{abstract}
This paper investigates the characteristics of US colleges and universities that were early adopters of post-1970 academic growth fields. It examines hypotheses drawn from four analytical perspectives on sources of organizational change: organizational ecology, inter-institutional stratification, demographic composition, and historical traditions. Focusing on 20 "newly established" and "emerging" growth fields, we find strong support for density-dependence and organizational size as influences on early adoption for all fields, as well as support for institutional status variables as influences on the early adoption of new liberal arts and basic sciences fields.
\end{abstract}

Keywords Organizational change - Diffusion of innovations - Colleges and universities · Curricula

The world of institutionalized knowledge in US colleges and universities has been changing dramatically over the last three decades. Higher education scholars have written extensively about the rise of occupational-professional programs (Brint et al. 2005; Turner and Bowen 1990), the responsiveness of universities to market signals and donor preferences in the development of new business and technology fields (see, e.g., Engell and Dangerfield 2005; Geiger 2004; Kirp 2003; Washburn 2005); the rise of interdisciplinary research and teaching (see, e.g., Brint et al. 2009; Jacobs and Frickel 2009; Klein 1996), and the response of universities to the changing demographic characteristics of students and faculty as an influence on the development of new "culture and identity" fields, such as ethnic studies and women's studies (see, e.g., Boxer 1998; Frank et al. 1994; Rojas 2007; Tobias 1978).

In this paper, we examine the institutionalization of high-growth fields in US four-year colleges and universities during the period, 1970-2006. The focus of the paper is on the

S. Brint $(\varangle) \cdot$ K. Proctor $\cdot$ R. A. Hanneman $\cdot$ K. Mulligan $\cdot$ M. B. Rotondi

University of California, Riverside, Riverside, CA, USA

e-mail: brint@ucr.edu

S. P. Murphy

University of South Florida, Tampa, FL, USA 
institutional locations of early adopters of these fields. From a sociological perspective, we believe early adopters are more important than the first innovators of new fields. Innovations that do not penetrate beyond a few schools are destined to fail, except perhaps as very small niche cultures. Only when a field has a foothold in a broader stratum of institutions is its future in academe relatively secure. The characteristics of early adopting institutions are therefore important for understanding how the structure of academically legitimated knowledge changes over time. Yet the existing literature on academic change has not paid close attention to the types of institutions that are early adopters of new fields.

We will show that the mechanisms by which new fields diffuse within the US system have much to do with competition effects within geographical contexts and with the dominant role played by large, high-enrollment institutions that have the capacity to staff new fields and to attract students to them. Special theories about status dynamics are necessary, however, to fill out the analysis of diffusion of new arts and sciences fields. These fields are fostered particularly by wealthier institutions with long traditions in the arts and sciences and, in the case of socially incorporative fields (such as women's studies and ethnic studies), also by public sector institutions.

\section{Analytical perspectives on early adoptors}

Our study is organized as a comparison of the explanatory power of four analytical perspectives. We develop hypotheses drawn from the literatures on organizational ecology, inter-institutional stratification, demographic composition, and historical traditions. We do not investigate all prominent perspectives on organizational change. With the exception of two fields (computer/information science and communications), those discussed in this paper show only partial diffusion through the system of US higher education during the period of our study. Consequently, neo-institutional theory, which emphasizes the widespread diffusion of dominant models through isomorphic processes (DiMaggio and Powell 1983), has little applicability to the topic of our analysis (cf. Morphew and Huisman 2002).

\section{Organizational ecology}

Organizational ecology explanations are based on the premise that the behavior of individual organizations is shaped by opportunities and constraints in their environment, and by the differential capacities of individual organizations to exploit opportunities and survive challenges (Hannan and Freeman 1989). For purposes of our analyses, we will treat ecological niches as the geographical areas in which organizations compete.

One key insight of organizational ecology is that niches have "carrying capacities" that place upper limits on the density (i.e. number of) organizations that can be sustained (Carroll and Hannan 2000: 222-7). For this reason, larger places have the potential to support more activities. Adoption rates, then, should be higher in geographical areas with larger populations, all else being equal. A second insight is that founding (and failure) rates of organizations (or programs) are density dependent. When there are very few other organizations in a niche that display a feature, adoption rates are likely to be low because organizations face great uncertainty about whether carrying capacity for a program exists. The success of early adopters, however, demonstrates that carrying capacity is present in the niche, and legitimates offering a competitive program. Hence, rate of new adoption should be a positive function of the number of organizations that have already founded a program. As the number of institutions in a niche offering a program increases toward the 
carrying capacity, competition for students and other resources grows, increasing barriers to entry and decreasing expected marginal returns to offering the program. This dual dynamic, legitimation and competition, suggests that the probability that an institution adds a program will be a quadratic function of the density of that program in its nicheincreasing with density and decreasing with density squared (Carroll and Hannan 2000: 216-7).

The capacity of an organization to exploit new niche space, or to succeed despite competition in a crowded one, can be a function of individual organizational characteristics as well as the density of competing organizations. For higher education institutions, a primary adaptive characteristic of interest is size (Blau 1994, Chap. 3). From an ecological perspective, size is an indicator both of organizational carrying capacity and potential student demand for new fields. Larger organizations have the capacity to hire and organize faculty in ways that allow for the adoption of new fields and a heightened opportunity to generate effective demand for courses and majors from their larger student bodies. For these reasons, we expect that larger institutions will be more likely to adopt new programs.

Assuming the ceteris paribus condition in these and all succeeding hypotheses, we test the following hypotheses:

H-1 Institutions located in larger population areas will be more likely to be early adopters of new fields.

H-2 Institutions located in geographical areas in which a low proportion of institutions have adopted a new field will be more likely to adopt the field.

H-3 Institutions located in geographical areas in which a high proportion of institutions have adopted a new field will be less likely to adopt the field.

H-4 Larger institutions will be more likely to adopt new fields.

Inter-institutional stratification

Since Veblen (1899), sociologists and economists have recognized a distinction between luxury and non-luxury goods. Social scientists have translated this distinction into expectations about educational stratification. For Collins (1977, 2000), lower-status institutions tend to focus on practical training in courses of study closely connected to jobs and occupations, while higher-status institutions tend to focus on esoteric fields of study distant from the labor market, the knowledge of which is embodied in complex linguistic codes and modes of appreciation that require many years of study to understand and are more likely to be found in families endowed with high levels of cultural capital (see also Bourdieu 1984, 1988). Drawing on this work, we expect financially less secure and socially less elite higher education institutions to be more likely to adopt new occupational-professional fields, while financially more secure and socially more elite institutions will be more likely to adopt new fields in the liberal arts and basic science disciplines.

Two primary indicators of institutional status in US higher education are wealth and selectivity. Wealthy institutions have large endowments and high operating budgets per student to support their educational and co-curricular missions. Selective institutions admit only the most qualified of the many thousands of students who apply for admissions each year. They are, in this respect, exclusive clubs to which the great majority of applicants will not be admitted (Frank 1999; Karabel 2005) and consequently we expect them to focus to a greater degree on status fields than practical fields. Moreover, students attending highstatus institutions are likely to have the resources and opportunities to delay training for 
their future jobs and occupations until graduate school, freeing them to study the liberal arts and basic sciences (Zhang 2005).

Highest degree offered is another, more functional, source of status differentiation. Doctoral-granting institutions play different roles and gain higher prestige in the academic system than masters' and baccalaureate granting institutions, because, in addition to their undergraduate teaching responsibilities, their faculties are the producers of new knowledge and are active in the production of the next generation of scholars and scientists. Doctoralgranting universities have shown a particularly strong historical emphasis on fields connected to science and technology (Geiger 1993; Geiger and Sa 2005, 2008; Graham and Diamond 1997). We expect doctoral-granting research universities to be associated with early adoption of new science and technology fields, and bachelor's degree granting institutions to be more likely to focus on well-established fields of study.

We test the following hypotheses:

H-5 Lower-status institutions will be more likely to adopt new occupational-professional fields.

H-6 Higher-status institutions will be more likely to adopt new liberal arts and basic science fields.

H-7 Doctoral-granting institutions will be more likely to adopt new science and technology fields.

Demographic composition

Two arguments have been made about demographic composition as a source of curricular change. The first has focused on the elective affinity between the life experiences of students from non-traditional groups and the rise of new curricula associated with those life experiences. This approach has linked the life experiences of lower SES students to preferences for more practical, job-relevant curricula (see, e.g., Cross 1971; Trow 1974) and the life experiences of female students to preferences for study in the arts, social services, and other historically sex-segregated fields (Jacobs 1996). A second argument is based on accommodation to political pressures for representation. Recent literature has pointed to the tendency of administrators to accommodate to the pressures of social movement organizations and changing faculty values by offering new curricula attuned to the interests of mobilized groups and progressive-minded faculty members (Boxer 1998; Olzak and Kangas 2007; Rojas 2007).

In higher education, racial-ethnic minorities and women are two groups of special interest. Since 1970, their numbers have grown dramatically as a proportion of undergraduate students enrolled in higher education institutions (US Department of Education, National Center for Education Statistics 2008: Table 226). Because members of racialethnic minorities more often come from immigrant and working class backgrounds, we expect that higher proportions of these students will be associated with early adoption of new occupational-professional fields, Because women have historically pursued (and been limited to) sex-typed occupations, we expect that higher proportions of women students will be associated with early adoption of sex-segregated fields in which women are more numerous (such as those in the arts and social services) and perhaps also reduced support for traditionally male fields (such as those in engineering and physical sciences). Following the second argument, we expect higher proportions of women and minorities to be associated with the adoption of women's studies and ethnic studies, respectively. 
We test the following hypotheses:

H-8 Institutions enrolling higher proportions of minority students will be associated with early adoption of new occupational-professional fields.

H-9 Institutions enrolling higher proportions of female students will be associated with early adoption of historically female-dominated fields.

H-10 Institutions enrolling higher proportions of female students will be associated with early adoption of women's studies.

H-11 Institutions enrolling higher proportions of under-represented minority students will be associated with early adoption of ethnic studies.

\section{Historical traditions}

Historical traditions are often cited as forces encouraging the reproduction of existing structures and as value-based restraints on change. Sociologists have emphasized the importance of values embedded in leaders (Selznick 1957), organizational sagas (Clark 1970), and ritual categories (Meyer and Rowan 1977) as bases of structural reproduction.

Two historical traditions are particularly important in US higher education. Liberal arts colleges and universities have been closely connected to the training of elites from the time of the colonial colleges (Baltzell 1964; Horowitz 1987). Today, not all institutions with commitments to the liberal arts and basic sciences are high-status; instead, small religiously-affiliated colleges are among the most likely to maintain these commitments (Brint et al. 2009). We expect that institutions with historical commitments to the liberal arts and basic sciences model will be more likely to welcome new arts and sciences fields.

Public universities in the land-grant tradition have had the opposite orientation from liberal arts colleges; they were constituted to provide practical training for men and women in agricultural and industrial occupations and were intended to be open to students from all social strata (Nevins 1962). Over time, the land grant tradition has become generalized throughout the public sector insofar as public universities present themselves as addressing the needs of the state and the economy for educated labor (Brint 2007; Geiger and Sa 2008). We consequently expect that public universities, as compared to private institutions, will be particularly receptive to new occupational-professional fields, and particularly receptive to new science and technology fields.

While historical traditions predispose institutions to maintain value commitments, brand-new institutions have no such loyalties. Following Stinchcombe (1965), we expect that absence of historical traditions will predispose institutions born after the beginning date of the time series to be more receptive to the high-growth fields of the era.

We test the following hypotheses:

H-12 Institutions historically committed to the liberal arts and sciences tradition will be associated with early adoption of new fields in the arts and sciences.

H-13 Public control will be associated with early adoption of new occupational-professional fields, and particularly with early adoption of new science and technology fields.

H-14 Institutions born during the period of the study will be associated with early adoption of new fields. 


\section{Data and methods}

\section{Study population}

We examined the adoption of fields in the core institutions in the US higher education system. We define "core institutions" as 4-year colleges and universities which offer a range of baccalaureate degrees, rather than degrees in only a small set of related programs. We therefore do not include specialized institutions, such as art schools, business colleges and seminaries. We also do not include for-profit institutions. The number of institutions in our population of core institutions increased by 200 during the 35-year period, from 1265 to 1465 , while the number of the baccalaureate degrees core institutions awarded annually increased from nearly 800,000 to more than 1.3 million.

\section{Defining established and emerging growth fields}

We examine the characteristics of institutions that offered undergraduate degrees in two types of high-growth fields during the period: (1) those that had become established by the end of the period and (2) those that had not yet become established, but had experienced comparable levels of growth. We refer to these as newly established and emerging fields, respectively.

We are interested in fields that demonstrated significant growth during our period of observation and, at the same, diffused relatively widely during the period. We define newly established fields as those that were offered by 20 percent or fewer institutions in 1970-1971, grew to include at least 10 percent more institutions during the period, and were offered by 20 percent or more of institutions in 2005-2006. We consider the 20 percent threshold a good marker that a field has "arrived" in academe, or, as some would say, reached the "take-off" point to sustainability (Rostow 1963). We define emerging fields as those that grew to include at least 10 percent more institutions during the study period, but continued to be offered at fewer than 20 percent of institutions by the last year in the study. We examine emerging fields because they showed the same minimal levels of growth during the period and, although not yet fully established, show sufficient growth to suggest that they may become established fields of the future.

Our field categorizations are based on HEGIS/IPEDS degree files, coded at 5 year intervals from 1970-1971 through 2005-2006. Higher education data was collected in the Higher Education General Information Survey (HEGIS) during the first two panel years. This data was collected in the Integrated Post-Secondary Educational Data System (IPEDS) in the last six panel years. From the initial HEGIS coding scheme, which existed in 1970-1971 and 1975-1976, field coding changed in four of our panel years: 1980-1981, 1985-1986, 1990-1991, and 2000-2001. In the process of degree differentiation during the period, the number of fields represented at the bachelor's level grew from 319 to 935 .

These changes required extensive work to align fields between the five categorizing schemes. We aggregated categories from later periods to match as closely as possible those used in earlier periods, using HEGIS and IPEDS crosswalks. ${ }^{1}$ In addition, we aggregated

\footnotetext{
${ }^{1}$ During the early years of our time series, for example, multi-disciplinary studies were exclusively focused on engineering specialties. This category expanded in later years of the series, but the coding in earlier years prevents direct comparisons. We were therefore unable to analyze the institutional locations of this 15 th high-growth field, multi-/interdisciplinary studies, due to the federal government's exclusive classification of engineering subspecialties as interdisciplinary during the first years of the series.
} 
closely connected fields so as to improve the statistical power of our analyses. For example, in the earlier period, all forms of sales and marketing were treated as an undifferentiated field. By the end of the period, a wide range of marketing degrees had been defined. We consequently aggregated all marketing fields (e.g., fashion marketing, travel and tourism marketing, automobile marketing, and marketing, general) to form a single "marketing" category. ${ }^{2}$

\section{Dependent variables}

We are interested in defining the types of institutions that provide the organizational base for new academic fields. Our unit of analysis is consequently the institution. We focus on defining the characteristics of early adopters of newly-established fields and adopters of emerging fields, and we use logistic regression and correspondence analysis to distinguish the characteristics of early adopters from those of late and/or non-adopters. ${ }^{3}$

We define early adopters as the first 20 percent of institutions ( \pm 2 percent) to offer degrees in the field. We measure early adoption from the date at which this 20 percent threshold was reached. The early adoption date, therefore, varies from field to field, as indicated in Table 1 . We chose the 20 percent threshold partially on practical grounds. During our panel years, we were able to define a 20 percent threshold ( \pm 2 percent) for all newly-established fields. We were not able to define a lower or higher threshold as precisely. Statistical and conceptual issues also influenced our choice of threshold. Statistically, the 20 percent threshold is preferable to lower thresholds because it allows for more robust analysis with lower standard errors around parameter estimates. ${ }^{4}$ Conceptually, higher thresholds, such as 25 percent, seemed to us to define groups of institutions larger than that implied by the term "early adopters."

For the newly-established fields, we compare the characteristics of early adopters to those of late and non-adopters, using the threshold year as the reference point. We examine the explanatory power of variables linked to each of the four interpretive frameworksorganizational ecology, inter-institutional stratification, demographic composition, and historical traditions-based on the hypotheses stated above. All measurements are taken at the date the field reached 20 percent diffusion. For emerging fields, we focus on whether or not institutions had ever adopted the field by 2005-2006. Again, we examine the explanatory power of variables linked to each of the four interpretive frameworks.

Newly-established and emerging fields, 1970-2006

Table 1 provides an overview of 14 newly established ${ }^{5}$ (panel A) and six emerging (panel B) fields during the period of our study.

\footnotetext{
${ }^{2}$ A table of correspondence is available on request.

3 We do not pool the data or use general estimating equations to predict diffusion patterns, because we are not interested in explaining diffusion curves. The speed of diffusion is a separate topic. The fields in this study include a few that diffused rapidly (e.g. computer/information science and communications) during the period and a few that showed only a slow rise to the 20 percent threshold or just beyond (e.g. applied design and international relations).

${ }^{4}$ Findings for emerging fields (see below) suggest that the same general pattern of organizational effects would have emerged had we adopted a 15 percent threshold for the newly-established fields.

5 Communications is a borderline case. It had been adopted by just over 20 percent of institutions in 1970-1971. We include it because it is very close to our threshold and is one of the fastest-growing fields during the period.
} 
Table 1 Growth fields, 1971-2006

\begin{tabular}{|c|c|c|c|c|c|}
\hline \multirow[t]{2}{*}{ Degree } & $1971(N$ & $=1,265)$ & 2006 & $=1,465)$ & \multirow{2}{*}{$\begin{array}{l}\text { Change in } \\
\% \text { Schools }\end{array}$} \\
\hline & Schools & $\begin{array}{l}\% \text { of } \\
\text { Schools }\end{array}$ & Schools & $\begin{array}{l}\% \text { of } \\
\text { Schools }\end{array}$ & \\
\hline
\end{tabular}

A. Newly established fields (10\% Plus Growth; Fewer than 20\% Schools by 1971; 20\% Plus Schools by 2006

\begin{tabular}{|c|c|c|c|c|c|}
\hline Computer and information science & 102 & 8.1 & 1,126 & 76.9 & 68.8 \\
\hline Communication studies & 263 & 20.8 & 981 & 67.0 & 46.2 \\
\hline Parks and recreation & 73 & 5.8 & 667 & 45.5 & 39.8 \\
\hline Criminal justice and corrections & 69 & 5.5 & 641 & 43.8 & 38.3 \\
\hline General studies and liberal arts & 138 & 10.9 & 706 & 48.2 & 37.3 \\
\hline Marketing/marketing management & 35 & 2.8 & 555 & 37.9 & 35.1 \\
\hline Environmental science and studies & 35 & 2.8 & 499 & 34.1 & 31.3 \\
\hline Social services & 176 & 13.9 & 592 & 40.4 & 26.5 \\
\hline Management information systems & 0 & 0.0 & 345 & 23.5 & 23.5 \\
\hline Nursing & 250 & 19.8 & 620 & 42.3 & 22.6 \\
\hline Biochemistry/molecular biology and microbiology & 127 & 10.0 & 426 & 29.1 & 19.0 \\
\hline Applied design & 76 & 6.0 & 357 & 24.4 & 18.4 \\
\hline Banking, finance, investment, and securities & 184 & 14.5 & 477 & 32.6 & 18.0 \\
\hline International relations & 82 & 6.5 & 295 & 20.1 & 13.7 \\
\hline \multicolumn{6}{|c|}{ B. Emerging fields (10\% plus growth; $10-20 \%$ schools by 2006) } \\
\hline International business & 24 & 1.9 & 282 & 19.2 & 17.4 \\
\hline Computer engineering, general & 0 & 0.0 & 181 & 12.4 & 12.4 \\
\hline Womens studies & 0 & 0.0 & 179 & 12.2 & 12.2 \\
\hline Health administration & 27 & 2.1 & 183 & 12.5 & 10.4 \\
\hline American ethnic studies & 36 & 2.8 & 189 & 12.9 & 10.1 \\
\hline Public policy and administration & 44 & 3.5 & 199 & 13.6 & 10.1 \\
\hline
\end{tabular}

Sources: US Department of Education (1971c, 2009)

Nine of the 14 newly-established fields during the period were occupational-professional; they are typically oriented to training students for employment in occupations. ${ }^{6}$ In order of their rates of institutionalization during the period, these fields were: computer/ information science, parks and recreation, criminal justice, marketing, social work, management information systems, nursing, applied design, and banking and finance. Statebased and social service fields (criminal justice, social work, nursing, and parks and recreation) were as numerous as business and technology fields (computer science, marketing, management information systems, and banking/finance). We also see the influence of gender in these fields. Three of the fields (nursing, social work, and applied design) have been female-dominated fields.

Arts and sciences fields, while less numerous, were not entirely absent. Five of the 14 were arts and sciences fields - that is, they expose students to a basic field of knowledge. In order of their rates of institutionalization during the period, these fields were

\footnotetext{
${ }^{6}$ Our classification of arts and sciences versus occupational-professional fields is based on the typology developed in Brint et al. (2005).
} 
communications, ${ }^{7}$ general studies, environmental science, cell and molecular biology, and international relations. General studies is a special case; although nominally arts and sciences, it has become used by colleges and universities as a multi-option "catch-all" major, often taken by students who struggle to succeed in traditional majors.

In addition, four of the six emerging fields were occupational-professional. In order of their rates of institutionalization, these were: international business, computer engineering, health administration, and public policy/public administration. Here too state-based fields (health administration and public policy/public administration) were as numerous as business or technology fields (international business and computer engineering). Two new culture and identity fields (women's studies and ethnic studies) were among the emerging fields.

Each of the occupational-professional fields creates a perceived pathway into primary sector occupations, whether in business, the state, or the health care system. The representation of arts and sciences fields demonstrates the continued relevance of the idea that, as culture producing institutions, colleges and universities have some autonomy from state and economy, and the substance of these fields helps to delineate the contemporary content and meaning of the phrase "some autonomy." Some high-growth arts and sciences fields have at least distant links to media or technology industries (communications, environmental science, cell and molecular biology); others to social movement organizations and demographic change (environmental studies again, as well as women's and ethnic studies); and still others to processes of globalization (international relations).

\section{Independent variables}

For purposes of predicting the locations of early adopters of newly-established and emerging fields, we measured four organizational ecology variables. Population is a measure of the carrying capacity of the institution's immediate geographical region. The term "core based statistical area" (CBSA) became effective in 2000 and refers collectively to metropolitan and micropolitan statistical areas (US Department of Education, National Center for Education Statistics 2009). We use CBSAs to define boundaries of the geographical space in which higher education organizations compete. We measured population retrospectively from the population of counties in the CBSA in which the organization resided. Two variables measure the coverage of a field within the geographical space defined by CBSAs. Adopting in Region is a measure of the number of higher education institutions within the CBSA that had adopted the field by its early adoption date (or, in the case of emerging fields, by the last year in the time series). We coded the number of institutions in each CBSA by locating institutions within counties covered by CBSAs. We coded the number of institutions adopting a program based on IPEDS data on degrees awarded in our target fields. Adopting in Region Squared is a measure of saturation. If most institutions within the organization's geographical frame have already adopted a field, the organization may not experience sufficient niche space to adopt. Enrollment is a measure of an organization's carrying capacity and potential demand for new fields. We measured size as total headcount enrollment from HEGIS/IPEDS enrollment data.

We measured four inter-institutional stratification variables corresponding to dimensions of hierarchical differentiation within the structure of US four-year colleges and

\footnotetext{
7 Although some communications curricula provide practical training for technical positions in the mass media industries, communications is primarily a liberal arts discipline in which most courses focus on rhetoric, communications practices in different institutional settings and cultures, public opinion, and the organization and consequences of mass media industries (Bertelsen and Goodboy 2009; Wardrope 1999).
} 
universities. Operating budget per student is a measure of organizational wealth. It is computed from HEGIS/IPEDS financial data, divided by headcount enrollment. ${ }^{8}$ We removed hospitals and independent operations from operating expenditures so as to focus on expenditures more closely connected to the quality of the undergraduate experience. ${ }^{9}$ Selectivity is measured from the Barron's admissions selector index. Barron's index is based on acceptance rates for freshmen applicants, as well as freshman students' high school ranks, grade point averages, and median SAT/ACT scores. The most competitive institutions have the lowest acceptance rates. Barron's applies only qualitative labels to its rankings, ranging from "most competitive" to "non-competitive." We assigned numeric values to these labels for the purpose of analysis, with one denoting the least selective and six denoting the most selective institutions. ${ }^{10}$ Doctoral granting is a measure of position within the functional hierarchy of higher education institutions. Doctoral granting institutions are defined as institutions awarding at least 30 doctoral degrees in a year. The 30 doctorate cutoff is adapted from Snyder and Hoffman's (2005) approach to generalizing the Carnegie Classification. ${ }^{11}$ Masters' granting institutions are defined as institutions awarding at least 30 masters degrees in a year and serve as the reference category. Baccalaureate granting institutions comprise the remaining institutions. They offer fewer than 30 masters degrees a year, again following Snyder and Hoffman (2005).

We measured two demographic characteristics of student bodies from HEGIS/IPEDS enrollment data. Percent minority is a continuous variable measured as non-white students as a proportion of total enrollment. Percent female is a continuous variable measured as women students as a proportion of total enrollment. ${ }^{12}$ We included as a control variable Percent international, a continuous variable measured as proportion of international students to total enrollment. We assumed that this variable might show net significant associations with early adopters of international fields.

We measured three variables related to historical traditions. Percent Liberal Arts 1970 is a measure of an institution's commitment to the traditional arts and sciences in the first year of the time series. This is a continuous variable coded from HEGIS/IPEDS degree data measured as the proportion of total degrees awarded in the arts and sciences, as opposed to occupational-professional fields, in the first year of our time series. We identify

\footnotetext{
${ }^{8}$ Based on consultation with the IPEDS lead analyst of financial data, Dr. Craig Bowen, we determined that valid comparisons could be made following the changes in accounting rules for private universities in 1997. For total expenses, lines E19 (FASB reporters) and C19 (for GASB reporters) are comparable (Bowen, personal communication).

9 Market value of endowment is another commonly used measure of wealth. Previous work (reference masked) indicates that operating budget/student and market value of endowment are highly correlated (above $r=.8$ ). Moreover, considerably more missing data exists on market value of endowment than on operating budget/student.

10 The years in the Barron's series are as follows: 1972, 1976, 1982, 1986, 1992, 1997, 1999, and 2007. The codes are contained in Fine (1972) and College Division of Barron's Educational Series (1976, 1982, 1986, 1992, 1997, 1999, 2007). We imputed values for the closest year of Barron's and our panel years.

11 The Carnegie Classification itself changed six times during the period of the study. Highest degree awarded has been a consistent element of the Carnegie Classification, but other elements have varied considerably across classification years. Although we find several of these classifications more informative than highest degree awarded, we were unable to reproduce what we consider the best of the classifications, Carnegie 1994, for earlier or later years in the series.

12 In separate analyses, we broke out historically black colleges and universities and all-women's colleges. Model efficiency, as measured by the Bayesian Information Criterion, was lower in the large majority of cases (22 of 26), and we consequently report models without these variables. The results of these analyses are available on request.
} 
institutions awarding high proportions of degrees in arts and sciences as historically connected to the liberal arts tradition. Public is a categorical variable measuring form of control and coded from HEGIS/IPEDS institutional characteristics. Emerged identifies institutions born after the beginning of the period of our study. This variable measures absence, rather than presence, of historical traditions. The variable is coded by eliminating degree-granting institutions appearing at the beginning of the period from those appearing at the end of the period. We included the variable Died as a control variable. These institutions appeared in HEGIS/IPEDS at the beginning of the time series, but no longer appeared by the end of the period. ${ }^{13}$ Descriptive statistics on the independent variables in this analysis are provided in "Appendix A".

\section{Methods}

Our first analysis is based on logistic regression, where the dependent variable is categorical and " 1 " is defined as an early adopting institution, or, in the case of emerging fields, an ever-adopting institution. We conducted these logistic regressions on each of the 20 fields.

We used correspondence analysis to complement the results of the logistic regressions. Correspondence analysis is a method of factoring variables and displaying them in a property space which maps their association in two or more dimensions (Clausen 1998). Rather than examining patterns of predictors across fields, this analysis forces predictors to align with particular fields, thereby indicating particularly strong affinities between institutional characteristics and academic fields. ${ }^{14}$

For the correspondence analysis, we reran logistic regressions to isolate only institutional characteristics for the set of institutions that existed throughout the period of the study. This approach avoids the difficulties of relating intrinsically relational (Adopting in Region and Adopting in Region Squared) and extra-institutional data (Population) to the correspondence between types of institutions and types of fields. The resulting visual representations provide a more sharply focused map of the correspondence of types of institutions and types of fields in two-dimensional space.

\section{Results}

We discuss results from the regression analyses first, followed by results from the correspondence analysis. Regression results for occupational-professional fields were different, in important respects, from results for arts and sciences fields. We therefore report results for occupational-professional fields in Table 2 and arts and sciences fields in Table 3.

\footnotetext{
${ }^{13}$ Reliance on IPEDS data may result in a small amount of measurement error in the emerged and died variables. Institutions may be reclassified for technical reasons as entirely new institutions by IPEDS if they are continuing under a different name or governing authority or have begun to admit new populations of students. Similarly, institutions may be treated as defunct because they did not, for whatever reason, report data to IPEDS in the final panel year. An independent examination of emerged and died institutions using Internet resources identified several ambiguous cases.

${ }^{14}$ In the analysis, we normalized the rows (predictors) and columns (fields) separately, and we found the singular values and eigenvalues of the matrix. We then scored and plotted the predictor variables and the fields on the first two singular values or eigenvectors. The analysis included both continuous and categorical variables. The method used for scaling gives approximately equal weight to the variation across predictor variables and to the variation across fields. Correspondence analyses were computed with UCINET 6.162 (Borgatti et al. (2002), using the Carroll-Green-Schaeffer transformation (Carroll et al. 1986, 1987). For a discussion of this approach and an alternative to it, see Faust (2005).
} 


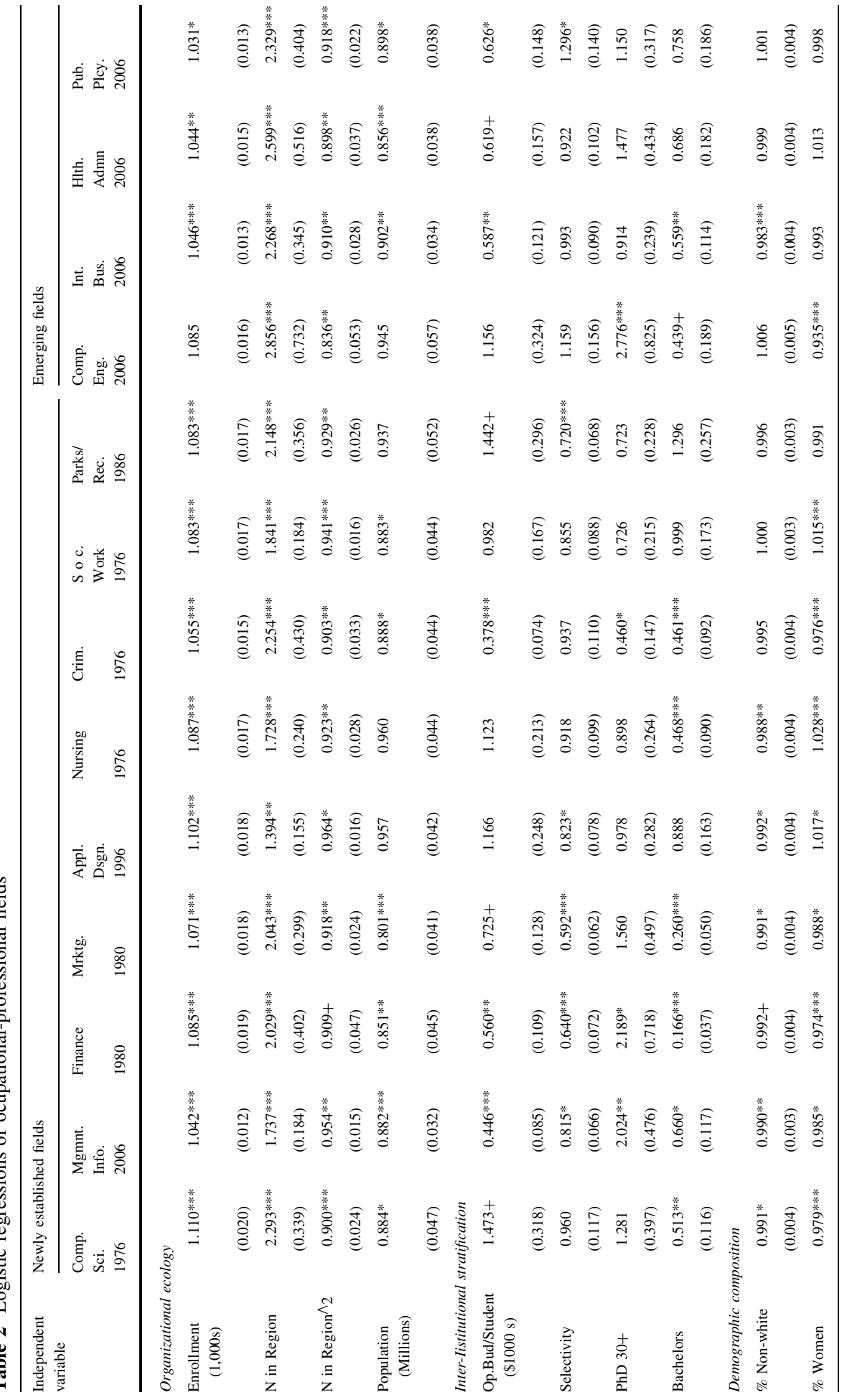




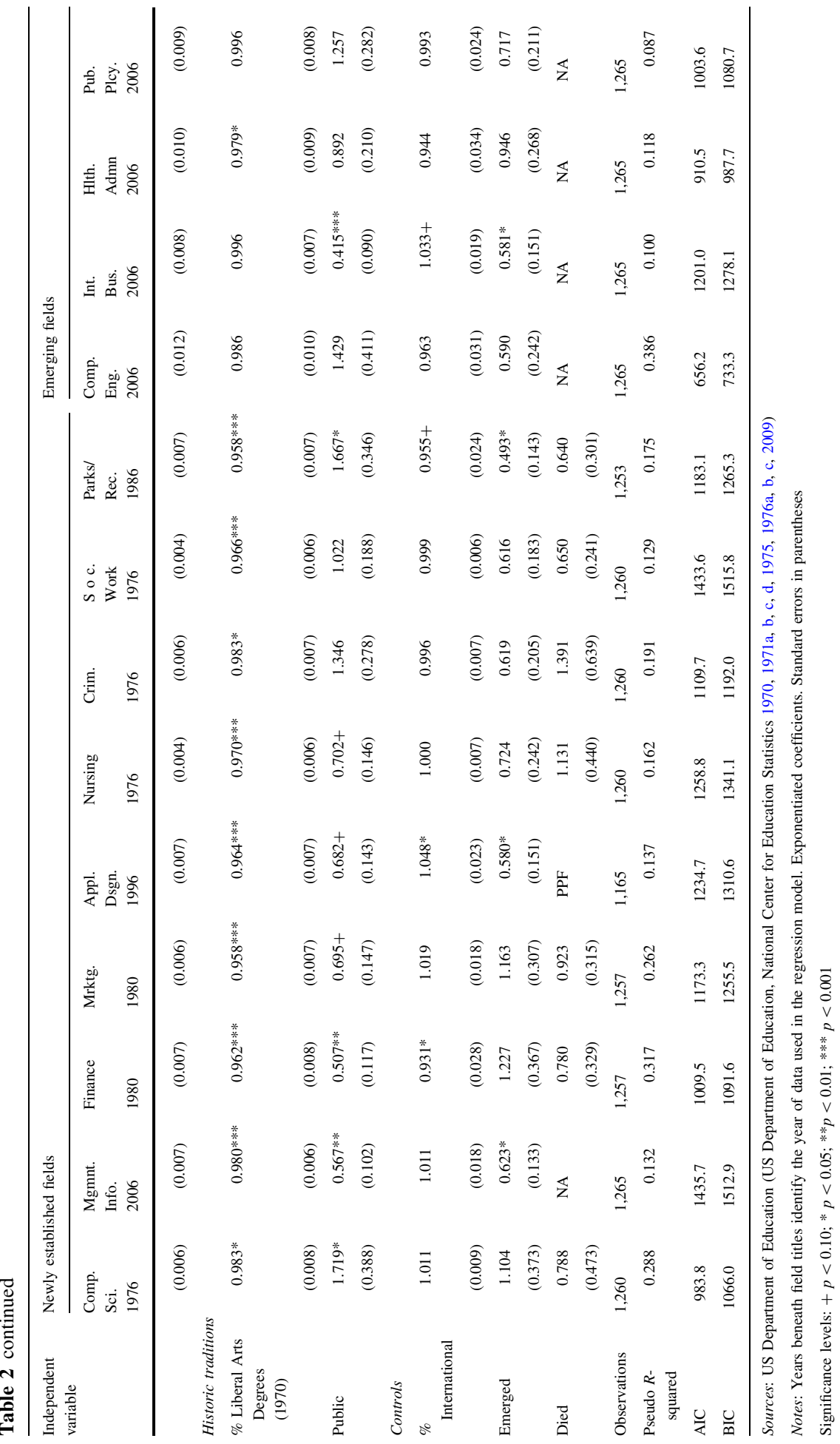




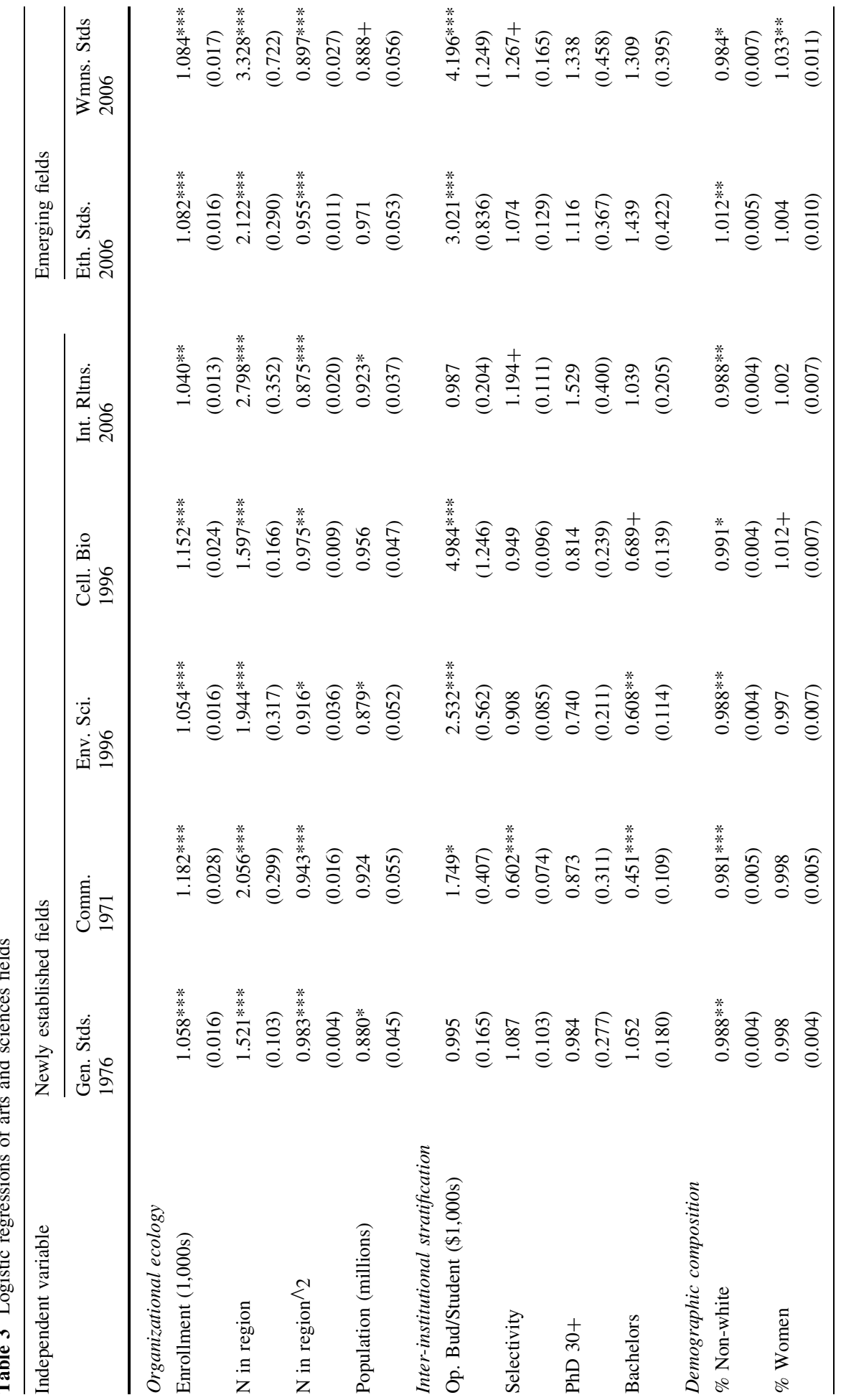




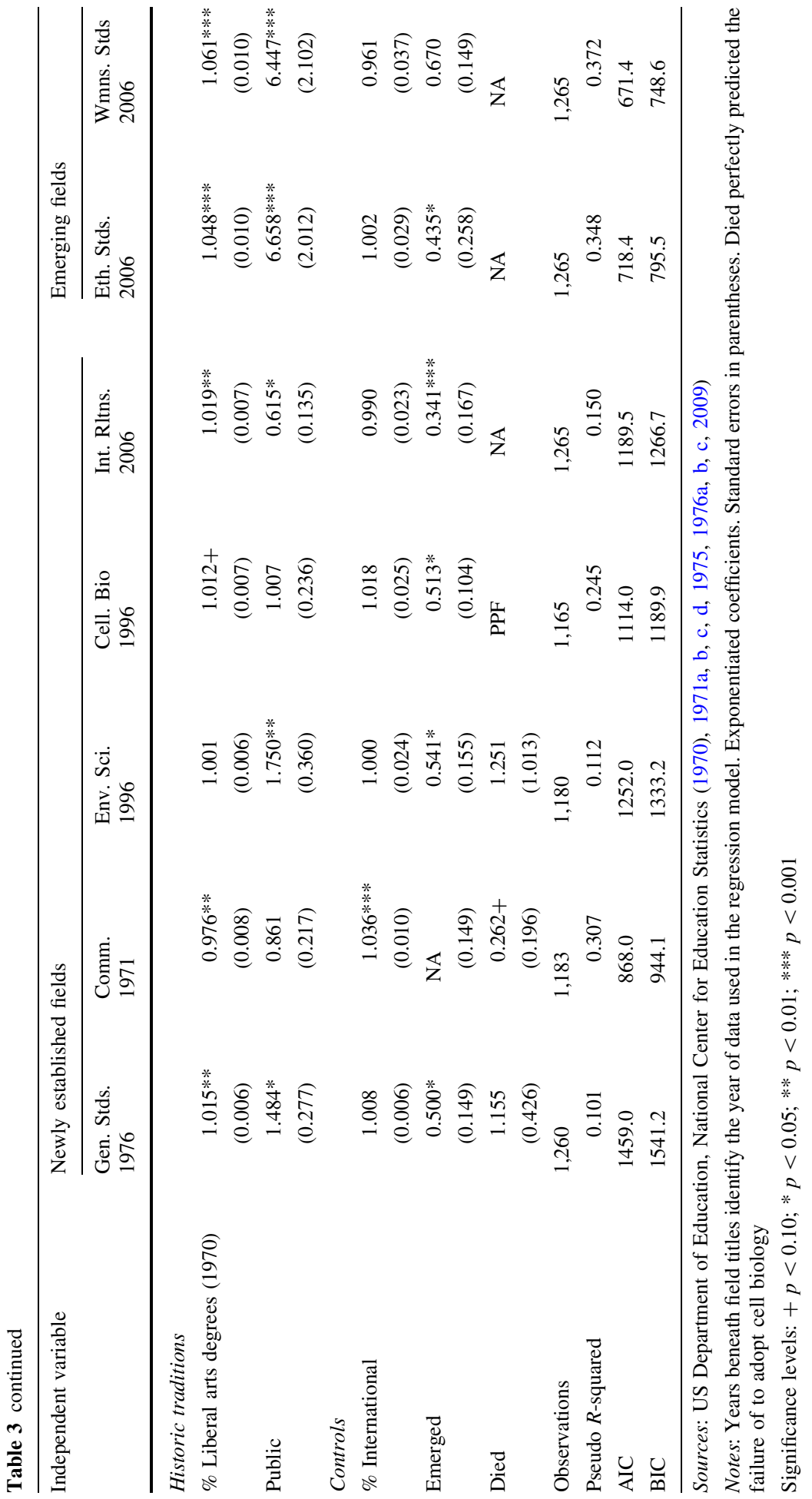


Results from the regression analyses

Ecological variables were strongly associated with early adoption across all 20 fields. Relatively large numbers of adopting institutions within the geographical area defined by the CBSA were associated with consistent and strong odds of adopting new fields, whether occupational-professional or arts and sciences. The squared term was also strongly associated with lower levels of adoption, indicating that within CBSAs when niche space is filled beyond a certain point no further adoption of fields is likely. Equally important, larger enrollment institutions were consistently and strongly associated with adoption of new fields, both in occupational-professional and arts and sciences fields. These results indicate that larger institutions have the carrying capacity to support new fields and may have the incentive as well to support them to cater to student (or potential student) interest on campus. Population was the only ecological variable that failed to show strong associations with the adoption of new fields. Indeed, larger population areas were frequently associated with lower probabilities of adoption, controlling for other significant covariates in the model. This suggests that the state of competition of organizations within a geographic area is the key to change, rather than the population of the area or even the sheer number of organizations competing in the area.

Institutional wealth, as measured by operating budget/student, showed the expected net associations with high-growth arts and sciences fields (other than international relations and the special case of general studies); it also showed significant negative net associations with several occupational-professional fields, particularly with new business fields. Wealthy institutions were very likely to adopt socially incorporative new culture and identity fields (ethnic studies and women's studies). These results indicate that institutional wealth is associated, as predicted, with a focus on status fields, and less often with a focus on practical, job-related fields. Similarly, as hypothesized, institutions with high levels of commitment to arts and sciences in 1970 were more likely to be early adopters of most new arts and sciences fields. They were also less likely to be adopters of new occupationalprofessional fields. We found little support, however, for selectivity as an influence on the adoption of arts and sciences fields. Instead, we found some evidence for it as a barrier to the adoption of new occupational-professional fields.

As hypothesized, baccalaureate-granting institutions were averse to adopting new fields. However, counter to our hypothesis, doctoral granting institutions were not consistently more likely to adopt new science and technology fields and instead were more likely to adopt new business fields. Nor were public institutions consistently more likely to adopt new science and technology fields, as we expected based on their land-grant origins. Instead, they were more likely to adopt the emerging culture and identity fields of women's and ethnic studies, indicating a special relationship between contemporary public sector institutions and historically marginalized population groups.

As hypothesized, institutions enrolling high proportions of women were more likely to adopt fields related to women's traditional occupational locations. Institutions enrolling high proportions of women also showed a tendency to avoid some technical fields, notably computer engineering. However, institutions enrolling higher proportions of minority students were less likely to adopt new occupational-professional fields, rather than more likely to do so. It is possible that these institutions seek the legitimacy and prestige of longestablished fields, rather than adopting the jobs-oriented practical approach we hypothesized.

Finally, institutions born during the study period showed no preference for the highgrowth academic fields of the period. 
Thus, we found consistent and strong support for hypotheses 2-4 (density dependence and size as influences on the early adoption of all new fields). We also found substantial support for hypotheses 5-6 (status effects on the early adoption of new arts and sciences fields), hypotheses 9-11 (proportion of women as an influence on the early adoption of female-dominated fields and the relation between demographic categories and the early adoption of women's and ethnic studies), as well as hypothesis 12 (arts and sciences tradition as an influence on the early adoption of new arts and sciences fields).

We found little or no support for the other hypotheses.

Results from the correspondence analysis

The correspondence analysis showed a good fit in two dimensions, with the first two dimensions accounting for 77 percent of the variance and the third dimension adding little.

As depicted in Fig. 1, one dimension in the correspondence analysis defined what we can conceive of as a "social change" vs. "corporate business" division linked to public and private institutions, respectively. Thus, the left-right axis in the correspondence analysis showed distinct affinities between public institutions and what we might term "social movement fields" (ethnic studies, women's studies, and environmental studies). It also

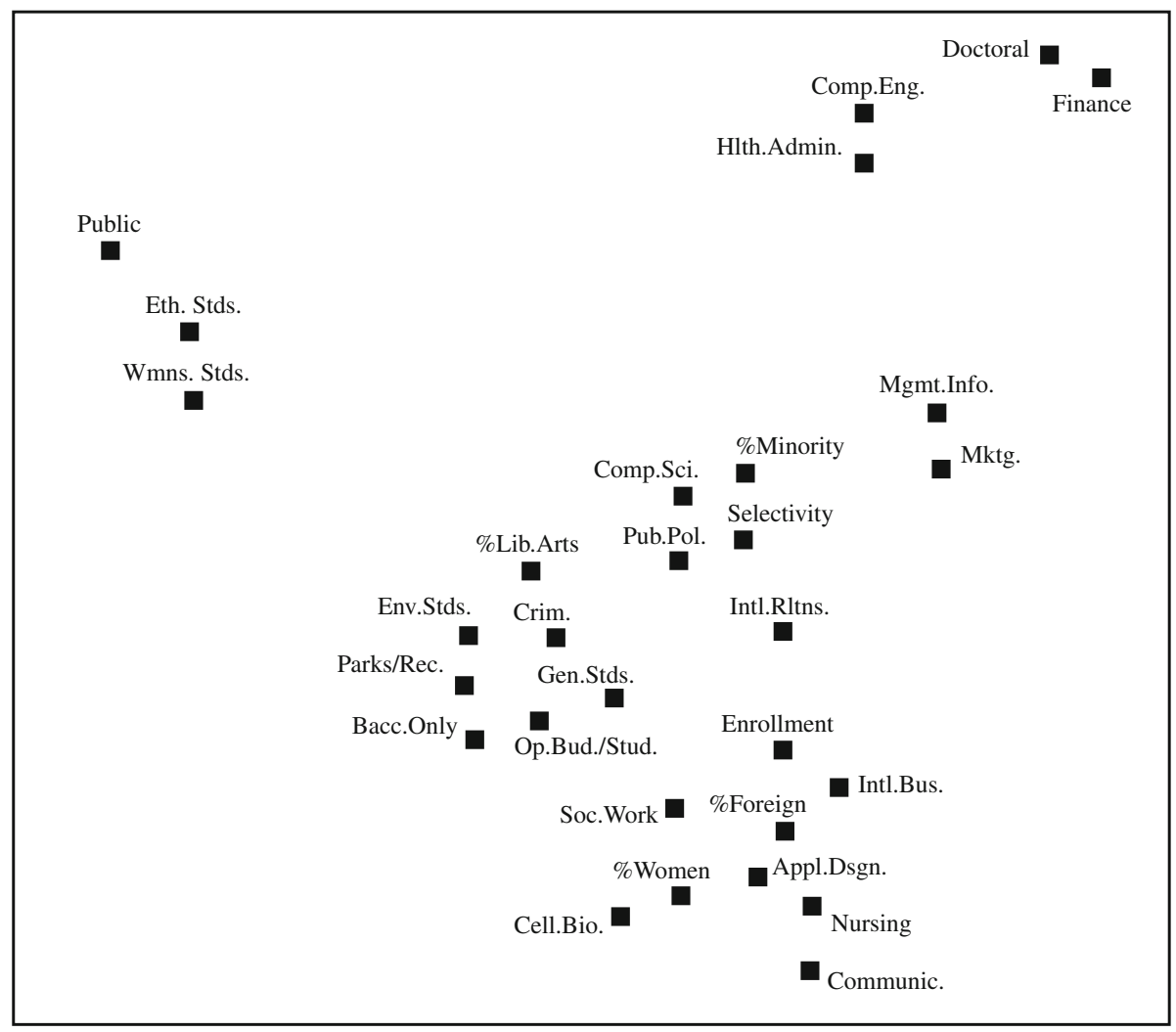

Fig. 1 Correspondence analysis. Source: HEGIS/IPEDS database, 1970-2006. Notes: Two factors account for $77 \%$ of the rescaled variance 
showed affinities between private institutions and several higher-income business and technology fields (finance, management information systems, marketing, international business, health administration, and computer engineering). The second dimension defined what we can conceive of as a "low-technology" vs. "high-technology" division linked most closely to doctoral and baccalaureate-granting institutions, respectively. Thus, the upper right sector showed a clustering of computer engineering, finance, and health administration closely associated with doctoral granting institutions, and the lower left sector showed a clustering of criminology, general studies, environmental studies, and parks and recreation most closely associated with baccalaureate granting institutions.

\section{Discussion}

The primary contribution of this paper has been to test hypotheses drawn from four perspectives on the dynamics of organizational change in higher education. The separate cross-sectional portraits we develop of early adopters, when examined together, open a window onto locations in the system that are receptive to new fields and also reveal some important patterns through which new fields diffuse in the system.

The diffusion of new fields is rarely system-wide. Among 14 newly established fields, only two (computer/information science and communications) diffused to even half of 4year colleges and universities by 2005-2006. Given this reality of partial and limited diffusion, the questions social scientists ask about academic change should be mainly about which types of institutions will be most receptive to new fields - and why?

We can answer these questions by focusing on consistent and strong net associations in the data, as reported in Tables 2 and 3. One part of the answer to these questions is that larger organizations are receptive to a wide range of new fields. As shown in the logistic regression results, high enrollment institutions were consistently and often strongly associated with early adoption of each one of the 20 growth fields in this study. Large organizations have the carrying capacity and the potential student markets to try out new fields, and they are receptive both to new occupational-professional and new arts and sciences fields. They are, in this sense, the academic omnivores. Without large organizations, less innovation would likely exist in the system, because too few institutions would have the critical mass to adopt emerging fields, or the assurance of enough students to support courses and majors offered in these new fields.

Second, the logistic regression results show that the dynamics of competition within geographical regions are very important to processes of diffusion. Encouraged by pioneering institutions, other institutions within a geographical area join to adopt new fields in order to compete for students interested in the field. We found consistent and strong influences of density dependence in these analyses, with a larger number of adopting institutions associated with higher likelihoods of early adoption. Once perceived saturation in a geographic area is reached, however, adoption slows down dramatically or ceases. Accordingly, we also found strong and consistent effects for the squared term of adopting institutions in a region.

Another part of the answer to these questions is that institutional status is consequential. Wealthier colleges and universities tended to support new arts and sciences fields and to resist early adoption of new occupational-professional fields. Institutions whose historical traditions favored the arts and sciences showed similar tendencies. The trend toward the growth of the "practical arts" in US higher education (Brint 2002) is consequently constrained, to some degree, by prestigious institutions that occupy dominant market positions 
and by historical traditions that distance institutions from the utilitarian, job-preparation interests of most undergraduate students and their parents (Astin 1998). This creates a counter-balance within a system otherwise favoring new occupational-professional fields and, together with omnivorous large institutions, additional sources for fostering new arts and sciences fields.

Finally, our findings point to potential institutional challenges facing new science and technology fields. Some traditional bastions of these fields are no longer consistently among their early adopters. Doctoral institutions showed more consistent net associations with early adoption of new business fields than with early adoption of new science and technology fields. ${ }^{15}$ Public universities showed more consistent net associations with early adoption of socially incorporative new culture and identity fields than with early adoption of new science and technology fields. Institutions enrolling higher proportions of women and minorities also showed lower levels of early adoption of new science and technology fields, a factor of interest because these two groups are the fastest-growing in US higher education.

Many commentators have pointed to the significance of new science and technology fields as engines of economic growth (see, e.g., Bush and 1990 [1945]; Drori et al. 2003; Geiger 1993; Geiger and Sa 2008; Graham and Diamond 1997; Kerr 1963). Our findings suggest under-appreciated institutional factors-the interest of doctoral institutions in business fields, the interest of public sector institutions in socially incorporative fields, and the weak scientific interests of many institutions enrolling high proportions of women and minorities - which may affect preparation for and diffusion of new science and technology fields in US four-year colleges and universities.

Open Access This article is distributed under the terms of the Creative Commons Attribution Noncommercial License which permits any noncommercial use, distribution, and reproduction in any medium, provided the original author(s) and source are credited.

\section{Appendix A}

See Table 4.

Table 4 Summary statistics of pooled independent variables, 1970-2006

\begin{tabular}{llccccc}
\hline Variable & $N$ & Mean & Std. Dev. & Min & Max & Percent \\
\hline Enrollment (1,000s) & 10,667 & 5.59 & 7.64 & .003 & 66.89 & - \\
Adopting in region & 10,730 & 2.55 & 4.43 & 0 & 31 & - \\
Op. Bud/student (\$1,000s) & 10,273 & 17.55 & 15.30 & .251 & 480.13 & - \\
Selectivity & 10,119 & 3.92 & 1.08 & 1 & 7 & - \\
PhD 30+ & 10,730 & .14 & .35 & 0 & 1 & 14 \\
Bachelors & 10,730 & .46 & .50 & 0 & 1 & 46 \\
\% Non-white & 10,730 & 24.72 & 26.73 & 0 & 100 & - \\
-\% Women & 10,667 & 55.53 & 15.93 & 0 & 100 & - \\
\% International & 10,730 & 5.12 & 14.65 & 0 & 100 & - \\
\% Liberal arts degrees (1970) & 10,730 & 33.41 & 13.09 & .427 & 100 & -
\end{tabular}

\footnotetext{
15 Some have hypothesized that this change in orientation among doctoral granting institutions reflects the exodus of mathematically inclined students into banking, finance, and other remunerative business fields (Chang et al. 2007).
} 
Table 4 continued

\begin{tabular}{llccccc}
\hline Variable & $N$ & Mean & Std. Dev. & Min & Max & Percent \\
\hline Public & 10,730 & .36 & .48 & 0 & 1 & 36 \\
Population (millions) & 10,730 & 1.07 & 2.47 & 0 & 18.76 & - \\
Emerged & 10,730 & .14 & .35 & 0 & 1 & 14 \\
Died & 10,730 & .06 & .23 & 0 & 1 & 6 \\
\hline
\end{tabular}

Notes: Observation of cases occurred at 5-year intervals

\section{References}

Astin, A. W. (1998). The changing American college student: Thirty year trends, 1966-1996. The Review of Higher Education, 21, 115-135.

Baltzell, E. D. (1964). The protestant establishment: Aristocracy and caste in America. New York: Viking.

Bertelesen, D. A., \& Goodboy, A. K. (2009). Curriculum planning: Trends in communications studies, workplace competencies and current programs at 4-year colleges and universities. Communications Education, 58, 262-285.

Blau, P. M. (1994 [1973]). The organization of academic work, 2nd ed. New Brunswick, NJ: Transaction Publishers.

Borgatti, S. P., Everett, M. G., \& Freeman, L. C. (2002). Ucinet for windows: Software for social network analysis. Harvard, MA: Analytic Technologies.

Bourdieu, P. (1984 [1979]). Distinction. Cambridge, MA: Harvard University Press.

Bourdieu, P. (1988 [1984]). Homo academicus. Stanford: Stanford University Press.

Boxer, M. (1998). When women ask the questions: Creating women's studies in America. Baltimore: Johns Hopkins University Press.

Brint, S. (2002). The rise of the 'practical arts'. In Steven. Brint (Ed.), The future of the city of intellect: The changing American university (pp. 231-259). Stanford: Stanford University Press.

Brint, S. (2007). Can public research universities compete? In R. L. Geiger, C. L. Colbeck, R. L. Williams, \& C. K. Anderson (Eds.), Future of the American public research university (pp. 91-118). Rotterdam, NL: Sense Publishers.

Brint, S., Proctor, K., Murphy, S. P., Turk-Bicakci, L., \& Hanneman, R. A. (2009). General education models: Continuity, change in the US undergraduate curriculum, 1975-2000. Journal of Higher Education, 80, 605-642.

Brint, S., Riddle, M., Turk-Bicakci, L., \& Levy, C. S. (2005). From the liberal to the practical arts in American colleges and universities: Organizational analysis and curricular change. The Journal of Higher Education, 76, 151-180.

Brint, S., Turk-Bicakci, L., Proctor, K., \& Murphy, S. P. (2009b). Expanding the social frame: The growth and distribution of interdisciplinary degree-granting programs in American colleges and universities, 1975-2000. Review of Higher Education, 32, 155-183.

Bush, V. (1990 [1945]). Science-The endless frontier. Washington: National Science Foundation.

Carroll, J. D., Green, P. E., \& Schaffer, C. M. (1986). Interpoint distance comparisons in correspondence analysis solutions. Journal of Marketing Research, 23, 271-280.

Carroll, J. D., Green, P. E., \& Schaffer, C. M. (1987). Comparing interpoint distances in correspondence analysis solutions: A clarification. Journal of Marketing Research, 26, 445-450.

Carroll, G. R., \& Hannan, M. T. (2000). The demography of corporations and industries. Princeton: Princeton University Press.

Chang, M. J., Park, J. J., Lin, M. H., Poon, O. A., \& Nakanishi, D. T. (2007). Beyond myths: The growth and diversity of Asian American college freshmen, 1971-2005. Los Angeles: Higher Education Research Institute, Graduate School of Education and Information Sciences, UCLA.

Clark, B. R. (1970). The distinctive college: Antioch, reed, and swarthmore. Chicago: Aldine.

Clausen, S.-E. (1998). Applied correspondence analysis. Thousand Oaks, CA: Sage Publications. Quantitative Applications in the Social Sciences Series No. 121.

College Division of Barron's Educational Series. (1976). Barron's profiles of American colleges. Woodbury NY: Barron's Educational Series.

College Division of Barron's Educational Series. (1982). Barron's profiles of American colleges. Woodbury NY: Barron's Educational Series. 
College Division of Barron's Educational Series. (1986). Barron's profiles of American colleges. Woodbury NY: Barron's Educational Series.

College Division of Barron's Educational Series. (1992). Barron's profiles of American colleges. Hauppauge NY: Barron's Educational Series.

College Division of Barron's Educational Series. (1997). Barron's profiles of American colleges. Hauppauge NY: Barron's Educational Series.

College Division of Barron's Educational Series. (1999). Barron's profiles of American colleges. Hauppauge NY: Barron's Educational Series.

College Division of Barron's Educational Series. (2007). Barron's profiles of American colleges. Hauppauge NY: Barron's Educational Series.

Collins, R. (1977). Some comparative principles of educational stratification. Harvard Educational Review, 47, $1-27$.

Collins, R. (2000). Comparative and historical patterns of education. In M. T. Hallinan (Ed.), Handbook of the sociology of education (pp. 213-239). New York: Kluwer Academic/Plenum Publishers.

Cross, K. P. (1971). Beyond the open door: New students to higher education. San Francisco: Jossey-Bass.

DiMaggio, P., \& Powell, W. W. (1983). The iron cage revisited: Institutional isomorphism and collective rationality in organizational fields. American Sociological Review, 48, 147-160.

Drori, G. S., Meyer, J. W., Ramirez, F. O., \& Schofer, E. (2003). Science in the modern world polity: Institutionalization and globalization. Stanford, CA: Stanford University Press.

Engell, J., \& Dangerfield, A. (2005). Saving higher education in the age of money. Charlottesville: University of Virginia Press.

Faust, K. (2005). Using correspondence analysis for joint displays of affiliation networks. In P. Carrington, J. Scott, \& S. Wasserman (Eds.), Models and methods in social network analysis (pp. 117-147). Cambridge, England: Cambridge University Press.

Fine, B. (1972). Barron's profiles of American colleges. Woodbury NY: Barron's Educational Series.

Frank, R. H. (1999). Luxury fever: Money and happiness in an era of excess. Princeton: Princeton University Press.

Frank, D. J., Schofer, E., \& Torres, J. C. (1994). Rethinking history: Change in the University Curriculum, 1910-90. Sociology of Education, 67, 231-242.

Geiger, R. L. (1993). To advance knowledge: The growth of American research universities, 1900-1940. New York: Oxford University Press.

Geiger, R. L. (2004). Knowledge and money: Research universities and the paradox of the marketplace. Stanford: Stanford University Press.

Geiger, R. L., \& Sa, C. (2005). Beyond technology transfer: New state policies for economic development for US universities. Minerva, 42, 1-26.

Geiger, R. L., \& Sa, C. (2008). Tapping the riches of science: Universities and the promise of economic growth. Cambridge, MA: Harvard University Press.

Graham, H. D., \& Diamond, N. (1997). The rise of American research universities. Baltimore: Johns Hopkins University Press.

Hannan, M. T., \& Freeman, J. (1989). Organizational ecology. Cambridge MA: Harvard University Press.

Horowitz, H. L. (1987). Campus life: Undergraduate cultures from the end of the eighteenth century to the present. New York: A. A. Knopf.

Jacobs, J. A. (1996). Gender inequality and higher education. Annual Review of Sociology, 22, 153-185.

Jacobs, J. A., \& Frickel, S. (2009). Interdisciplinarity: A critical assessment. Annual Review of Sociology, $35,43-65$.

Karabel, J. (2005). The chosen: The hidden history of admission and exclusion at Harvard, Yale, and Princeton. Boston: Houghton-Mifflin.

Kerr, C. (1963). The uses of the university. Cambridge, MA: Harvard University Press.

Kirp, D. L. (2003). Shakespeare, Einstein, and the bottom line: The marketing of higher education. Cambridge, MA: Harvard University Press.

Klein, J. T. (1996). Crossing boundaries: Knowledge, disciplinarity, and interdisciplinarities. Charlottesville: University Press of Virginia.

Meyer, J. W., \& Rowan, B. (1977). Institutionalized organizations: Formal structure as myth and ceremony. American Journal of Sociology, 83, 340-363.

Morphew, C. C., \& Huisman, J. (2002). Using institutional theory to reframe research on academic drift. Higher Education in Europe, 27, 491-506.

Nevins, A. (1962). The state universities and democracy. Urbana-Champaign, IL: University of Illinois Press.

Olzak, S., \& Kangas, N. (2007). Ethnic, women's and African American studies majors in U.S. institutions of higher education. Sociology of Education, 81, 163-188. 
Rojas, F. (2007). From black power to black studies: How a radical social movement became an academic discipline. Baltimore: Johns Hopkins University Press.

Rostow, W. W. (1963). The economics of take-off to sustained growth. New York: St. Martins.

Selznick, P. (1957). Leadership in administration. New York: Harper and Row.

Snyder, T. D., \& Hoffman, C. M. (2005). The condition of education 2005. Washington, DC: U.S. Department of Education.

Stinchcombe, A. L. (1965). Social structure and organizations. In J. G. March (Ed.), Handbook of organizations (pp. 142-193). Chicago: Rand-McNally.

Tobias, S. (1978). Women's studies: Its origins, its organization and its prospects. Women's Studies International Quarterly, 1, 85-97.

Trow, M. (1974). Problems in the transition from elite to mass higher education. Berkeley: Carnegie Commission on Higher Education.

Turner, S. E., \& Bowen, W. G. (1990). The flight from arts and sciences: Trends in degrees conferred. Science, 250, 517-521.

US Department of Education, National Center for Education Statistics. (1970). Higher Education General Information Survey (HEGIS), 1970: Fall enrollment [computer file]. ICPSR version. Washington DC: US Department of Education, National Center for Education Statistics [producer], 1970. Ann Arbor MI: Inter-university consortium for political and social research [distributor], 1998. doi:10.3886/ ICPSR02058.

US Department of Education, National Center for Education Statistics. (1971a). Higher Education General Information Survey (HEGIS), 1970-1971: Financial statistics [computer file]. ICPSR version. Washington DC: US Department of Education, National Center for Education Statistics [producer], 1971. Ann Arbor MI: Inter-university Consortium for Political and Social Research [distributor], 1998. doi: 10.3886/ICPSR02096.

US Department of Education, National Center for Education Statistics. (1971b). Higher Education General Information Survey (HEGIS), 1970-1971: Financial statistics [computer file]. ICPSR version. Washington DC: US Department of Education, National Center for Education Statistics [producer], 1971. Ann Arbor MI: Inter-university Consortium for Political and Social Research [distributor], 1998. doi: 10.3886/ICPSR02096.

US Department of Education, National Center for Education Statistics (1971c). Higher Education General Information Survey (HEGIS) V: Institutional characteristics of colleges and universities, 1970-1971 [computer file]. ICPSR 02111-v2. Washington DC: US Department of Education, National Center for Education Statistics [producer], 1971. Ann Arbor MI: Inter-university Consortium for Political and Social Research [distributor], 2005-09-12.

US Department of Education, National Center for Education Statistics (1971d). Higher Education General Information Survey (HEGIS) VI: Degrees and other formal awards conferred between July 1, 1970 and June 30, 1971 [computer file]. ICPSR 02138-v2. Washington DC: US Department of Education, National Center for Education Statistics [producer], 1971. Ann Arbor MI: Inter-university Consortium for Political and Social Research [distributor], 2005-11-04. doi: 10.3886/ICPSR02138.

US Department of Education, National Center for Education Statistics. (1975). Higher Education General Information Survey (HEGIS) IX: Institutional characteristics, 1974-1975 [computer file]. ICPSR 02044-v2. Washington DC: US Department of Education, National Center for Education Statistics [producer], 1971. Ann Arbor MI: Inter-university Consortium for Political and Social Research [distributor], 2005-10-26. doi: 10.3886/ICPSR02044.

US Department of Education, National Center for Education Statistics. (1976a). Higher Education General Information Survey (HEGIS), 1975: Fall enrollment [computer file]. 2nd ICPSR version. Washington DC: US Department of Education, National Center for Education Statistics [producer], 1976. Ann Arbor MI: Inter-university Consortium for Political and Social Research [distributor], 1998. doi: 10.3886/ICPSR07649.

US Department of Education, National Center for Education Statistics. (1976b). Higher Education General Information Survey (HEGIS), 1976: Higher education finance [computer file]. ICPSR version. Washington DC: US Department of Education, National Center for Education Statistics [producer], 1971. Ann Arbor MI: Inter-university Consortium for Political and Social Research [distributor], 1998. doi: 10.3886/ICPSR02096.

US Department of Education, National Center for Education Statistics. (1976c). Higher Education General Information Survey (HEGIS) XI: Degrees and other formal awards conferred between July 1, 1975 and June 30, 1976 [computer file]. ICPSR version. Washington DC: US Department of Education, National Center for Education Statistics [producer], 1976. Ann Arbor MI: Inter-university Consortium for Political and Social Research [distributor], 2005-11-04. doi: 10.3886/ICPSR02143. 
US Department of Education, National Center for Education Statistics. (2008). Digest of education statistics 2008. Washington DC: Government Printing Office.

US Department of Education, National Center for Education Statistics. (2009). IPEDS Data Center. Nces.ed.gov. Retrieved October 5, 2009 (http://nces.ed.gov/ipeds/datacenter/DataFiles.aspx).

Veblen, T. (1899). The theory of the leisure class: An economic study of institutions. London: Macmillan Publishers.

Wardrope, W. J. (1999). A curricular profile of U.S. communications departments. Communications Education, 48, 256-258.

Washburn, J. (2005). University, inc.: The corporate corruption of higher education. New York: Basic Books.

Zhang, L. (2005). Advance to graduate education: The effect of college quality and undergraduate majors. The Review of Higher Education, 28, 313-338. 